\title{
Los servicios locales de naturaleza económica. Municipalización, concesión y autorización
}

\author{
José Luis Sánchez Díaz \\ Magistrado. Presidente de la Sección 8. ${ }^{\text {a }}$ de la Sala \\ de lo Contencioso Administrativo de la Audiencia Nacional
}

\begin{abstract}
SUMARIO: 1. INTRODUCCIÓN. II. LOS SERVICIOS ECONÓMICOS EN EL REGLAMENTO DE SERVICIOS DE LAS CORPORACIONES LOCALES. III. MUNICIPALIZACIÓN Y CONCESIÓN DE SERVICIOS: A) Delimitación de los servicios económicos. B) La prestación en régimen de exclusividad de los servicios locales. IV. LA AUTORIZACIÓN REGLAMENTADA COMO ALTERNATIVA AL RÉGIMEN CONCESIONAL. CONFIGURACIÓN DE UN MODELO DEL RÉGIMEN DE AUTORIZACIONES O LICENCIAS PARA SERVICIOS LOCALES DE NATURALEZA ECONÓMICA, BASADO EN: 1. La utilización de la reglamentación. 2. La creación de Organismos o Comisiones de control. 3. El control local de las condiciones de instalación y acceso a las redes públicas. 4. Implantación reglamentaria de un servicio universal. 5. Posibilidad de establecer obligaciones específicas. 6. Delimitación de espacios compensatorios. 7. Utilización indistinta de la vía contractual o unilateral. 8. Establecimiento de un sistema de tasas financiador de actividades públicas. 9. Otorgamiento mediante licitación de las licencias individuales con limitación de número. V. CONCLUSIONES.
\end{abstract}

\section{INTRODUCCIÓN}

En 1872 se concede al Consejo de Estado francés la justicia delegada y se crea el Tribunal de Conflictos para dirimir los que surjan entre la jurisdicción civil y la administrativa; en 1914 comienza la 1. ${ }^{a}$ Guerra Mundial que va a suponer un protagonismo de la organización estatal en la actividad privada. En este periodo republicano, de corte liberal, el Consejo de Estado francés elabora el dogma del servicio público junto a otro gran principio que arranca de la revolución de 1789, el de la proclamación de la primacía del individuo frente al Estado y el reconocimiento de la existencia de derechos naturales e imprescriptibles del hombre.

Queda así esbozada materia propia del Derecho administrativo: De un lado, al existir la sospecha de que el gobierno atente contra los derechos naturales e impresciptibles del ser humano, surge la necesidad de limitar y controlar a la Administración Pública; y, de otro, la necesidad de que ésta disponga de los medios y prerrogativas adecuadas para salvaguardar los intereses que administra. La primera exigencia provoca la limitación y el control de la Administración. La segunda origina un par- 
ticular derecho basado en principios distintos a las que modelan relaciones privadas ${ }^{1}$.

Surge, durante la primera mitad del siglo $\mathrm{xx}$, un intento de sistematizar doctrinalmente cuanto se refiere al servicio público. Léon Duguit (Droit Constitutionnel, segunda Edición 1923, tomo 2) Maurice Hauriou (Précis elementaire de droit administratif, Paris, Lib. du Recueil Sirey, 1950); Marcel Waline (Traité élémentaire de Droit admintratif, Paris, 1950) BonNARD (Précis de Droit administratif. Paris, 1943), Gaston Jèze (Principios Generales de Derecho Administrativo. Traducción a la 3. a edición francesa, Buenos Aires 1949).

El núcleo esencial de la doctrina que estos autores propugnaban se centra en precisar que el servicio público constituye la actividad a realizar por la Administración. El servicio público se convierte en el eje del Derecho administrativo y abarca toda la actividad de la Administración asumida por razones de interés público.

El servicio público se configura, además, como el instrumento idóneo para que el Estado pueda atender las necesidades que urge la sociedad. Cooperan a ello la ideología intervencionista y además la preocupación de las Administraciones por dar satisfacción a las necesidades sociales y económicas que demandaba la época. En el ámbito normativo se ocupan de la municipalización de servicios el Estatuto Municipal de Calvo Sotelo, la Ley Municipal de 1935 y la Ley de Bases de Régimen Local de 17 de julio de 1945, Texto Refundido de 1955.

La expansión prestadora de servicios llega incluso al ámbito industrial y mercantil provocando una primera crisis de la teoría clásica del servicio público al ser ésta insuficiente para abarcar una realidad tan variada que alcanza la entrega de bienes materiales al mercado, y obliga a distinguir entre servicios públicos que se prestan de modo concurrente con la iniciativa privada y otros con carácter excluyente. En España se ocupa de ello el profesor VILLAR PALASí cuando publica «La Actividad Industrial del Estado en el Derecho Administrativo» en el año $1950^{2}$. Las notas de exclusividad regalista y el procedimiento de imperio, señala este autor, no se dan en la gestión económica. La rigidez normativa del Derecho público dificulta sobremanera la actividad de empresas que se desenvuelven por su propia naturaleza en el círculo de los negocios privados y, por ello, preci-

\footnotetext{
${ }^{1}$ Prosper WeIL: «El Derecho administrativo», Cuadernos Taurus núm. 74, p. 29.

${ }^{2}$ Revista de Administración Pública n. ${ }^{\circ} 3$.
} 
san de un régimen jurídico flexible que es el Derecho privado, principalmente del Derecho mercantil. Se trata de dar o entregar bienes al mercado, como actividad regida por principios distintos a los de la clásica teoría del servicio público. Este criterio, sin embargo, no es compartido por otros autores. La insuficiencia de la teoría del servicio público para este nuevo campo de actuación no genera, en opinión de éstos, la elaboración doctrinal de una nueva categoría dogmática. Así, García Oviedo-MarTínEz UsERoS señala que la actividad industrial puede constituir y constituye verdadero servicio público, entre otras razones, porque el régimen jurídico exorbitante del Derecho común no es indispensable a la actual concepción del servicio ${ }^{3}$. El Reglamento de Servicios de las Corporaciones Locales de 17 de junio de 1955 acoge, junto a normas jurídico-públicas, remisiones a formas de actuación mercantiles en el ámbito de los modos de gestión de los «servicios públicos». La Ley de Régimen Local de 1955 y el Reglamento citado parecían vislumbrar un futuro en el que en el municipio y la provincia iban a asumir múltiples y variados servicios de naturaleza, mereciendo por ello el elogio de municipalistas. Así, Luis MARQUÉs CARBó, en sus Comentarios al Reglamento de Servicios de las Corporaciones Loca$l e s^{4}$, señalaba que «la municipalización supone un progreso: se dirige en último análisis a asegurar al vecindario los elementos básicos de la vida civilizada». Pero este autor ya vislumbraba la crisis del movimiento municipalizador, que efectivamente se produjo, con el transcurso de los años impulsada por la progresiva asunción de competencias del Estado y la carencia de medios financieros de las entidades locales, privando a los municipios de la autonomía que el fenómeno municipalizador implicaba.

Dicho Reglamento tiene como eje vertebral la gestión de los servicios públicos, sin embargo, incorpora tres capítulos, relacionados con la acción administrativa local que trascienden del ámbito de los modos de gestión incluidos en el título tercero. Nos referimos al título primero que se ocupa de la intervención administrativa en la actividad privada; al título segundo referente a las subvenciones; y al título cuarto, dedicado a la «Cooperación provincial a los servicios municipales», aspecto este último meramente instrumental respecto a la prestación del servicio y a la ejecución de la obra pública. En este índice general reglamentario es claro que el aspecto «prestaciones» prima sobre el resto del contenido reglamentario. Cuando se dicta el Reglamento el tema preocupante para el legislador era la forma de gestión de los servicios. Sin embargo, el Reglamento se ocupa también de la intervención administrativa, vislumbrando la interrelación entre acti-

\footnotetext{
${ }^{3}$ Derecho Administrativo, 9. ${ }^{a}$ ed. vol. 2, 1968, p. 280.

${ }^{4}$ P. 57, comentario del artículo 45 .
} 
vidad privada y actuación pública y configurando una regulación adelantada en su momento, digna del mayor elogio.

Los valores del Reglamento de Servicios de las Corporaciones Locales son tan importantes y ajustados a un juicio de racionalidad que, cuando entra en vigor la Constitución española de 1978, aún mantienen su vigencia casi en su totalidad y pueden servir de pauta a toda la actuación administrativa local.

Sin embargo, cabe hacer una reflexión sobre dicho Reglamento a la luz de la propia Constitución y de la normativa comunitaria europea de aplicación.

\section{LOS SERVICIOS ECONÓMICOS EN EL REGLAMENTO DE SERVICIOS DE LAS CORPORACIONES LOCALES. SU ADAPTACIÓN A LA CONSTITUCIÓN Y AL DERECHO COMUNITARIO}

La Constitución española se ha ocupado muy extensamente de los derechos del ciudadano en sus relaciones con la Administración, en lo que afecta a sus derechos individuales y sociales, pero no lo hace con igual extensión cuando se refiere a las relaciones económicas entre la Administración y los ciudadanos. El legislador constitucional fue, quizás intencionadamente, parco en este punto, posiblemente porque era su intención dar flexibilidad a tal regulación o porque tal extremo podría ser objeto de regulación en el Derecho comunitario europeo, pudiendo constituir un obstáculo una regulación más detallada.

Los dos preceptos básicos al respecto son el artículo 38 y el artículo 128 del texto constitucional. De ellos resulta que, en principio y con carácter general, a las entidades locales se les reconoce iniciativa en la actividad económica. Además, la Ley puede reservar al sector público recursos o servicios esenciales, especialmente en caso de monopolio, y asimismo acordar la intervención de empresas, cuando así lo exigiere la intervención general. Ello ha tenido su proyección en la actual Ley Básica de Régimen Local (artículo 86 y en el Texto Refundido de régimen local, artículos 95 al 110 ). Ambos preceptos constituyen los pilares del Derecho administrativo económico, del que se ocupó extensamente Sebastián MARTín-Retortillo, que tenemos el honor de recordar en este trabajo, en su Derecho Administrativo Económico, publicado en 1988 por la Editorial «La Ley», al señalar que no cabe establecer prevalencia ni subordinación entre los artículos 38 y 128 de la Constitución 
pues «es necesario asumir de forma conjunta el contenido de los mismos» (p. 99).

Por otra parte, el Derecho comunitario supone con relación a la actividad desplegada por la Administración un significativo cambio de sentido. Conforme al esquema anterior a la incorporación de España a la Comunidad Económica Europea la actuación administrativa se centraba y tenía por eje vertebral la actividad de prestación o de servicio. En el Derecho comunitario se observa, en cambio, un desplazamiento de la Administración hacia la actividad de control o de intervención en el ámbito de las relaciones económicas para garantizar la libre concurrencia en el mercado. Además, la Administración, si participa en la actividad económica, lo ha de hacer sin prerrogativas que supongan una ventaja sobre los demás operadores en el mercado. Se desplaza así la finalidad de la acción administrativa del servicio público a las medidas de control del mercado, no para interferirlo sino precisamente para garantizar un régimen económico competitivo que comporta cuatro libertades:

1. Libertad de entrada en el mercado con pluralidad de ofertas en los servicios.

2. Libertad de acceso a la red y a las infraestructuras sobre las que descansa la prestación de los servicios.

3. Libertad de contratación y formación competitiva de los precios, y

4. Libertad de inversión 5 .

La Administración en virtud de este planteamiento debe controlar internamente los servicios económicos que gestiona para que ajusten su actuación a las normas comunitarias y debe también controlar externamente, mediante los modos de intervención apropiados, a los agentes $\mathrm{u}$ operadores económicos para que éstos alcancen iguales objetivos. Las prerrogativas de la Administración se han de encaminar a la consecución de estos fines utilizando técnicas administrativas de control, apropiadas en cada caso. Es en ello en lo que el Reglamento de Servicios precisa una revisión para sistematizar, y puntualizar más que los modos de gestión, los modos de control, tanto interno como externo, de la actuación pública y privada en las actividades y servicios económicos, según nos encontremos ante una actividad prestacional gestionada por la propia Administración o ante una actividad económica realizada por los particulares o empresas. Y

\footnotetext{
${ }^{5}$ Gaspar Ariño, Principios de Derecho Público Económico, 1999, p. 568.
} 
debe también ocuparse del posible contenido de la reglamentación de las actividades privadas, técnica ésta típicamente anglosajona. Cabe destacar, empero, que muchos de los principios reiteradamente señalados por nuestro Tribunal Constitucional, relativos a la intervención en materia económica, fueron adelantados ya en el Reglamento de Servicios de las Corporaciones Locales. Así, el principio de proporcionalidad en la intervención pública se halla recogido en el artículo 6.1, cuando señala que el contenido de los actos de intervención será congruente con los motivos y fines que los justifiquen; el de aplicación de la norma menos restrictiva de la libertad individual en el artículo 6 párrafo segundo; el de igualdad ante la ley en el artículo 2; el de legalidad en artículo 11 en relación con el artículo 5 .

La reforma del Reglamento de Servicios constituye también una buena oportunidad para ajustar el régimen de las subvenciones al Derecho comunitario, aunque cabe decir también que los preceptos que el Reglamento dedica a ellas no pueden ser más acertados: serán nulos — dice- los acuerdos de subvenciones que obedezcan a mera liberalidad (artículo 27.1); las subvenciones tendrán carácter voluntario y eventual, excepto lo que se dispusiere legal o reglamentariamente; la Corporación podrá revocarlas o reducirlas en cualquier momento salvo cláusula en contrario; no podrán ser invocables como precedente; la Corporación podrá comprobar, por los medios que estime oportunos, la inversión de las cantidades otorgadas en función de sus adecuados fines.

Sin embargo, el Reglamento de Servicios de las Corporaciones Locales debe adaptarse a las normas comunitarias en las subvenciones otorgadas a servicios económicos en la medida que pueden distorsionar la libre concurrencia en el mercado. En este sentido resulta procedente señalar que las subvenciones otorgadas a concesionarios o particulares que gestionan servicios económicos de interés público pueden distorsionar la competencia; no siendo conforme con el Derecho comunitario utilizar la subvención como un modo de alcanzar la exclusividad en la prestación de un servicio económico.

En términos generales la adaptación del régimen local español al Derecho comunitario supone una potenciación de una forma determinada de actuación administrativa, la de control, desplazando el eje central de la actividad prestacional a la actividad de control sobre los servicios económicos, para que éstos se ajusten al principio de libre concurrencia; pero uno y otro modo de actuación siguen siendo objeto del Derecho administrativo. Cada materia del Derecho administrativo responde a necesidades propias. En la actual Unión Europea se ha puesto el acento en algunos de 
esos problemas, singularmente en el tema de la competencia y el control del mercado, lo que coincide con un momento de bonanza económica y de ideología liberal, pero ello no quiere decir que los principios y técnicas de actuación elaboradas con relación al «servicio público» sean abandonados, con mayor razón si las circunstancias o la coyuntura económica determinasen la necesidad de aplicarlos.

\section{MUNICIPALIZACIÓN Y CONCESIÓN DE SERVICIOS}

\section{A) Delimitación de los servicios económicos}

Hecho un planteamiento general sobre la incidencia de la Constitución y el Derecho comunitario en el Reglamento de Servicios de las Corporaciones Locales con relación a los servicios públicos económicos vamos a examinar un aspecto puntual del tema, que se refiere a la municipalización, y por extensión provincialización de los servicios locales, y a la concesión como forma de gestión; instituciones ambas estrechamente interrelacionadas, puesto que una y otra se refieren a actividades o servicios económicos, cuyo incremento y tecnificación son notorios en la actualidad.

Generalmente en el ámbito de la economía se entiende por servicios económicos aquellos que, siendo escasos, pueden aportar un beneficio de tal naturaleza a quien los presta, por cubrir una necesidad individual o colectiva. Desde un punto de vista legal, este concepto tiene un alcance más limitado con relación a los servicios que pueden ser prestados por particulares, pues elimina de tal consideración aquellas actividades que suponen o llevan implícito el ejercicio de funciones públicas, incluyendo no sólo las que implican ejercicio de autoridad (artículos 69 del RSC y 95 del TRRL), sino además los que llevan implícita una función pública como serían los servicios fedatarios o certificantes reservados a quienes ejerzan una función secretarial. Tampoco serían otorgables a la iniciativa privada los servicios de seguridad pública, sin perjuicio de que los servicios privados de seguridad puedan realizar una actuación complementaria de aquellos como actividades privadas de carácter reglamentado. Respecto a las antiguamente denominadas actividades benéficas, muchas de ellas se han transformado en actividades susceptibles de rendimiento económico. Incrementado el nivel de vida y la capacidad económica de los ciudadanos no cabe desconocer la posibilidad de rendimientos económicos de guarderías, residencias de ancianos y otros centros de acogida. Sólo si estas actividades se prestan con fines benéficos y no con la pretensión de obtener un beneficio económico tales actividades dejarían de tener la considera- 
ción de servicios económicos a los efectos previstos en el artículo 86.1 de la Ley de Bases de Régimen Local y 97 de su Texto Refundido.

Tienen también la consideración de servicios económicos locales los servicios urbanísticos (abastecimiento de agua, eliminación y tratamiento de aguas residuales, entre otros, que el propio artículo 86 de la L.B.R.L. incluye entre los reservados a los entes locales como servicios esenciales). Precisamente la posibilidad de obtención de beneficios ofreciendo al mercado suelo urbanizado ha originado formas de participación privada en el proceso urbanizador. Así, la concesión de obra urbanizadora y la figura del «agente urbanizador», que se recoge en la Ley 2/1998, de 4 de junio, de Ordenación del Territorio y la actividad urbanística de Castilla-La Mancha, en la que se distingue entre una gestión directa (artículo 126) y una gestión indirecta, (artículo 127). En semejante sentido la Ley 6/1994 de la Comunidad Valenciana.

\section{B) La prestación en régimen de exclusividad de los servicios económicos locales}

Dicho esto, los servicios económicos locales pueden ser prestados, según lo expuesto, tanto por la Administración como por los particulares. $\mathrm{Si}$ estos servicios son prestados por particulares la Administración puede ejercer un control sobre los mismos en el ámbito de sus competencias, definidas por la Ley estatal y autonómica. Este control, de naturaleza externa, es más intenso en el ámbito de los servicios privados de interés general que en el resto de las actividades privadas de naturaleza económica, a través de la correspondiente reglamentación. Partiendo pues de una situación de libertad económica y de libre competencia es cuestionable la necesidad y viabilidad de la concesión. La concesión se configura en el Reglamento de Servicios de las Corporaciones Locales como un modo de gestión en el que la Administración ejerce un control externo sobre una actividad económica, gestionada por particulares y configurada como un servicio público. Surge aquí el problema de precisar la diferencia entre concesión de servicio público y autorización de servicio privado de interés público sujeto a reglamentación. La cuestión se centra en determinar qué aporta la concesión frente a la autorización reglamentada. En ambos casos se ejerce un control externo por la Administración sobre la actividad desarrollada, sin embargo, si en un régimen de libre concurrencia el particular puede desarrollar la actividad económica, bastándole una autorización, es obvio que la concesión debe suponerle un plus en el ámbito de sus derechos económicos que no tenía inicialmente como ciudadano. La res- 
puesta a esta cuestión viene dada porque la concesión tal como se configura en el Reglamento de Servicios de las Corporaciones Locales supone una situación de exclusividad frente al resto de los operadores en el mercado. Prueba de ello es que el periodo durante el que se otorga la concesión se calcula en razón al beneficio obtenible por el cobro de tarifas, en un mercado no competitivo. Esta nota de exclusividad empero entendemos que no es compatible con el principio de libre competencia en el ámbito económico que proclama el Derecho comunitario europeo, como más adelante precisaremos.

La Constitución permite que, mediante ley, determinadas actividades económicas de carácter esencial queden reservadas al sector público. El artículo 86 párrafo $3 .^{\circ}$ de la Ley de Bases de Régimen Local declara la reserva en favor de las entidades locales de determinadas actividades o servicios esenciales: abastecimiento y depuración de aguas; recogida, tratamiento y aprovechamiento de residuos; suministro de calefacción; mataderos y lonjas centrales; transporte público. Según Sebastián MARTíN-RetortiLlo, la reserva se identifica con la asunción de un servicio o actividad con carácter exclusivo, «apartando a los demás» (p. 251 obra citada). Señala también el artículo 86 citado que el Estado y las Comunidades Autónomas, en el ámbito de sus respectivas competencias, puedan establecer, mediante ley, idéntica reserva para otras actividades y servicios. Precisa además que la «efectiva ejecución» de estas actividades en régimen de monopolio requiere un procedimiento específico que culmina con la aprobación por el órgano de gobierno de la Comunidad Autónoma. El artículo 95 del texto Refundido de Régimen Local, aprobado por Real Decreto legislativo 761/1986, permite también que los servicios públicos locales, incluso los ejercidos en virtud de la iniciativa pública prevista en el artículo 86 de la Ley 7/1985, de 2 de abril, puedan ser gestionados directa o indirectamente.

Los servicios que enumera el artículo 86 son de naturaleza económica y además implicando la concesión la nota de exclusividad en la prestación, puesto que de no ser así bastaría una mera autorización para su ejercicio efectivo, surge el problema que antes hemos adelantado de determinar si la concesión de servicios locales, calificables de económicos es compatible con las libertades, antes referidas, que proclama el Derecho comunitario; sobre todo, si tenemos en cuenta que no parece muy razonable que, tras ser reservados estos servicios a la Administración por razones de interés público, e incluso prestados en régimen de monopolio, sea beneficiario de esta situación un particular o empresa privada, eliminando al resto de los posibles competidores. Para dar respuesta a esta cuestión hacemos las siguientes puntualizaciones: 
1) La situación de monopolio puede constituir uno de los posibles beneficios que en exclusiva puede beneficiar al concesionario, pero esta situación de exclusividad puede comprender otros posibles beneficios como son, la exclusividad por razón de la utilización del dominio público, la exclusividad otorgada en virtud del planeamiento urbanístico, la basada en el otorgamiento de la condición de beneficiario del ejercicio de potestades administrativas o la lograda mediante el otorgamiento de subvención. Un estudio detallado de cada una de estas situaciones de privilegio se efectuaba en la obra La concesión administrativa en la esfera local, publicada por el Instituto de Estudios de Administración Local en $1976^{6}$.

2) La legislación local vigente no hace referencia expresa a la municipalización o provincialización de servicios. $\mathrm{Ni}$ en el artículo 86.1 de la Ley de Bases de Régimen Local ni en el texto Refundido de la Ley de Régimen Local se alude expresamente a los términos municipalización o provincialización, aunque estos preceptos pueden conducir, en una posible interpretación de los mismos, a entender que se mantienen ambas figuras ${ }^{7}$.

El concepto de municipalización, extensible al de provincialización, suscitó diversas interpretaciones, estando vigente el Texto Refundido de la Ley de Régimen Local de 24 de julio de 1955 y el Reglamento de Servicios de las Corporaciones Locales (artículo 45) que se refiere a la asunción en todo o en parte del riesgo de la empresa «mediante el poder de regularla y fiscalizar su régimen». Sobre la municipalización CLAVEro Arévalo sostenía, en el prólogo a los Comentarios al Reglamento de Servicios de las Corporaciones Locales de MARQués CARBó, que la idea de gestión directa, heredada de la Ley italiana de 1903, no constituía su esencia, añadiendo que ésta consiste «en la sustitución del control externo que la Administración tiene en todo servicio concedido o arrendado por un control interno», que define como «la participación, en mayor o menor grado, de la corporación en la formación de la voluntad del ente que lleva a cabo la gestión del servicio municipalizado o provincializado. A veces este control es tan absoluto, que se identifica con la propia voluntad de la corporación y entonces estamos en presencia de una forma de municipalización que es la gestión directa. En otras ocasiones el control no es tan absoluto y ello nos explica la razón de que existan otras formas de municipalización, que no constituyen ni gestión ni explotación directa. Lo fundamental del concepto actual de municipali-

\footnotetext{
${ }^{6}$ José A. López Pellicer y José L. SÁnchez Díaz, La concesión administrativa en la esfera local: servicios, obras y dominio público, IEAL, Madrid, 1976.

${ }^{7}$ Así lo expresa López Pellicer en su obra Lecciones de Derecho administrativo, vol. 2. ${ }^{\circ}$, Murcia 1989, p. 150.
} 
zación y provincialización es el control interno administrativo en la entidad que explote el servicio».

GARCÍA DE ENTERRÍA señaló al respecto la necesidad de desvincular la asunción de la titularidad del servicio de la gestión directa ${ }^{8}$.

Partiendo de esta distinción la municipalización se identificaba con la asunción de la titularidad de un servicio económico local, bien en régimen de concurrencia o de monopolio. Legalmente, sin embargo, era cuestionable si se podía conceder el servicio tras haber sido asumida su titularidad en régimen de monopolio. La legislación local posterior aceptó esta posibilidad admitiendo, en el artículo 95 del Texto Refundido del Régimen Local de 18 de abril de 1986, que una vez reservado el servicio a la Administración éste podía ser gestionado bien directamente, bien indirectamente mediante concesión: añadiendo el artículo 104 de dicho texto legal que, cuando las entidades locales utilicen la forma de sociedad mercantil o cooperativa, cuyo capital social sólo parcialmente pertenezca a la entidad, ésta podrá aportar exclusivamente la concesión, lo que evidencia que se aporta algo, valorable económicamente que los particulares no tienen, cual es el control monopolistico de mercado.

La legislación de la actual Unión Europea potencia la autorización frente al régimen concesional, pues no admite situaciones de monopolio económico si no están justificadas por razones excepcionales de interés público.

Los textos legislativos ponen de relieve que la concesión comporta un privilegio, cual es la exclusividad en la prestación del servicio valorable económicamente. Esta situación de exclusividad ya no resulta de la antigua municipalización con monopolio, de la que ya no se habla en la L.B.R.L, sino de la efectiva ejecución de las actividades o servicios en régimen de monopolio, que puede estar determinada por factores de diversa índole, además de la asunción en exclusiva del servicio económico, como hemos dicho.

Tras la entrada en vigor de la Constitución española (artículo 128.2), resulta claro que las entidades locales pueden ejercer la iniciativa pública para el ejercicio de actividades económicas, mediante expediente acreditativo en el que se valore la conveniencia y oportunidad de la medida, sin que ello suponga una declaración de administrativa de asunción de tal actividad. La municipalización constituye, por tanto, una expresión trasnochada e innecesaria tras la aplicación del artículo 128.2 de la Constitución. Es

\footnotetext{
${ }^{8}$ «La actividad industrial y mercantil de los municipios», $R A P$, n. ${ }^{\circ} 17$, p. 109.
} 
más, para determinados servicios económicos como son los urbanísticos, su ejecución por los particulares constituye un deber, si se pretende transformar el suelo en urbano, actividad ésta de indudable valor económico.

Tampoco cabe desconocer que el otorgamiento de un monopolio, a través de la concesión, supone una ruptura del principio de libre concurrencia en la prestación del servicio. La concesión no se ajusta a este principio y además es sustituible por la licencia o la autorización reglamentada como más adelante veremos.

La jurisprudencia del Tribunal de Justicia de la Comunidad Europea ha reiterado que el derecho de establecimiento y la libre prestación del servicio es un principio fundamental del Tratado y confieren a los beneficiarios derechos individuales que las jurisdicciones nacionales deben salvaguardar y tienen primacía sobre toda norma nacional que le sea contraria (S. 7 de julio de 1976, asunto Waston). El artículo 64 del Tratado establece que los Estados miembros «se declaran dispuestos a proceder a una liberalización de los servicios»... si su situación económica general y la del sector afectado se lo permiten ${ }^{9}$.

Pero los controles por parte de la Administración deben respetar los límites que impone el Derecho comunitario, y fundamentalmente los que derivan de la libre prestación de servicios «que no puede resultar ilusoria y cuyo ejercicio no puede ser sometido a la discreción de la Administración».

Las Directivas comunitarias han precisado al respecto el alcance de la libertad económica en determinados servicios.

La jurisprudencia comunitaria ha admitido excepciones a la libertad de establecimiento y prestación de servicios económicos por razones de interés público, pero ha precisado al efecto, en estos casos, que los controles por parte de la Administración deben respetar los limites que impone el Derecho comunitario, y, fundamentalmente, los que derivan de la libre prestación de servicios «que no puede resultar ilusoria y cuyo ejercicio no puede ser sometido a la discreción de la Administración». Además, las Directivas Comunitarias han obligado a los Estados miembros de la Unión a regular la prestación de los servicios económicos en régimen liberalizado. (Así, las Directivas 90/387/CEE del Consejo, de 28 de junio de 1990

\footnotetext{
${ }^{9}$ Véase Victoria Abellán Honrubia, «La contribución de la jurisprudencia del Tribunal de Justicia de la Comisión Europea a la realización del derecho de establecimiento y la libre prestación de servicios», en Derecho Comunitario Europeo y su aplicación judicial, Civitas, 1993, p. 800.
} 
y 97/51/CE del Parlamento Europeo y del Consejo, en materia de Telecomunicaciones). Merece especial atención por su alcance general para el sector publico la Directiva 80/723/CEE de la Comisión, sobre transparencia de las relaciones financieras entre Estados miembros, entendiendo por empresa pública cualquiera «en la que los poderes públicos pueden ejercer, directa o indirectamente, una influencia dominante en razón de la propiedad, de la participación financiera o de las normas que la rigen», destacando al respecto Ramón PeÑalver, con cita a S. MuÑoz Machado, que este concepto inicial evolucionó hasta quedar desprovisto de cualquier matiz orgánico en la S.T.J. de 16 de junio de 1987, y en la Sentencia del Tribunal Supremo de 28 de septiembre de $1978{ }^{10}$.

Tan sólo puede estar justificada la situación de exclusión del mercado a otros competidores cuando lo exija inevitablemente la adecuada prestación del servicio, bien porque suponga la utilización privativa del dominio público, bien porque la efectiva prestación de la actividad exija una situación de tipo excluyente eliminadora de la concurrencia (monopolios naturales); pero incluso en este supuesto la concesión puede ser sustituida por la licencia o autorización otorgable previa licitación. En definitiva y en conclusion, por las razones expuestas los párrafos 3 y $4 .^{\circ}$ del artículo 86 de la LBRL exigen una interpretación restrictiva respecto a la aplicación de servicios monopolizados y posteriormente concedidos en virtud, de las previsiones legales que hemos citado. Ésta es la línea que ha seguido el legislador con relación a determinados servicios públicos estatales que antes se otorgaban por concesión. Así, en materia de telecomunicaciones la Ley 11/1998, de 24 de abril, prescinde de la concesión y acude al régimen de autorizaciones generales y licencias para otorgar la prestación de este servicio, que ya no se califica como servicio público sino como «servicio de interés general que se presta en régimen de competencia»; y en el mismo sentido en materia de comunicaciones marítimas en el que se prescinde del régimen concesional y se establece el de autorización.

\section{LA AUTORIZACIÓN REGLAMENTADA COMO ALTERNATIVA AL RÉGIMEN CONCESIONAL}

Conforme a lo expuesto, la concesión del servicio de interés general no se configuraría como la forma general de gestión de servicios económicos de interés público, sino como una forma excepcional aplicable tan solo a

\footnotetext{
10 «Problemática jurídica de la organización y régimen jurídico de la empresa pública», Cuadernos de Derecho Jurídico, Año 1996, en el volumen colectivo La intervención administrativa en la economía.
} 
los denominados «monopolios naturales». Los demás servicios económicos de interés público podrán ser prestados por las empresas en régimen de autorización administrativa adecuadamente reglamentada para la defensa de los intereses públicos. Las condiciones de este tipo de autorización vienen a sustituir a las obligaciones de servicio público, que se imponían al concesionario para su prestación. Se potencia así la función de control externo de la Administración sobre la iniciativa privada; control que se ejerce internamente sobre los servicios gestionados por la propia Administración; y externamente sobre la actividad privada.

El precedente de este tipo de autorizaciones en el Régimen Local español se encuentra en el artículo 17.2 del Reglamento de Servicios de las Corporaciones Locales. Este artículo, siguiendo la doctrina francesa de los servicios virtuales, permitía la reglamentación de servicios privados prestados al público cuando éstos implicaban la utilización especial o privativa de los bienes de dominio público. Con tal enfoque su previsión normativa era aplicada al servicio de taxis y otros semejantes. Esta figura de la que se ocupó el profesor EnTRENA CUESTA ${ }^{11}$, fue objeto de crítica por dicho autor, señalando al respecto, con acierto, que no era necesario acudir a la utilización del dominio para establecer una reglamentación de las actividades privadas de interés público, pues la vinculación al mismo constituía título suficiente para reglamentar la actividad.

La reglamentación de actividades privadas es una técnica muy utilizada en el Derecho anglosajón; y supone, como señala Gaspar ARIÑo, el abandono del concepto de reserva con todo el régimen jurídico que este concepto lleva consigo (titularidad a favor del Estado, idea de concesión como transferencia de una competencia originariamente administrativa, con rescate en cualquier momento, garantía del equilibrio financiero de la empresa, etc.) ${ }^{12}$.

Precisamente los sectores del agua y de la energía plantean en la actualidad la necesidad de establecer mecanismos legales que permitan una regulación coordinada y eficiente. En EE.UU. la «Comisión General Reguladora de la Energía», que funciona como agencia independiente encargada de regular el mercado nacional del petróleo, el gas y la electricidad, ha propuesto al Congreso que estableciera normas de obligado cumplimiento para todos los Estados con el fin de garantizar un nivel mínimo de eficiencia por parte de las compañías privadas ${ }^{13}$.

\footnotetext{
11 «El servicio de taxis», $R A P$ n. ${ }^{\circ} 27$, p. 29 y ss.

12 Obra citada, p. 573.

13 Véase El País, de 18 de agosto de 2003, p. 4, Sección internacional.
} 
El fallo en el suministro de energía eléctrica en Nueva York y en parte de la costa Este de EE.UU. y de Canadá ha supuesto un acicate para volver a estudiar y reconsiderar los desequilibrios territoriales en el suministro de energía eléctrica. Según el diario citado, la senadora demócrata María Cantwell ha señalado que la «desregulación del sector eléctrico que ha dejado indefensos a los consumidores, ha suprimido las garantías de un servicio fiable y ha eliminado la salvaguardia frente a la manipulación del mercado». También ha suscitado en EE.UU. polémica sobre la interdependencia territorial en los servicios básicos de energía.

España en la Ley núm. 55-1957, reguladora del sector eléctrico, abandona la tradicional gestión del mismo como servicio público liberalizando el transporte y la distribución de la electricidad, y estableciendo una única red que es puesta a disposición de los diferentes sujetos del sistema eléctrico y de los consumidores. Ello determina la necesidad de una reglamentación adecuada; pero pronto veremos que la cuestión es extensible a otros servicios económicos que afectan al ámbito local como el abastecimiento, suministro y tratamiento de agua potable, especialmente si se mantiene la política de trasvases entre cuencas hidrográficas, en el que se ven implicados Comunidades Autónomas. Y municipios. Incluso en el tratamiento y aprovechamiento energético de residuos y otras fuentes de energía como el gas. Problema éste que tiene su proyección en el ámbito de la organización y funcionamiento de la Administración pública, impulsando la creación de organismos interterritoriales que naturalmente superarían el ámbito de una cuenca fluvial determinada o de un centro generador de energía y su red de distribución.

La reglamentación debe perseguir que el funcionamiento de los servicios económicos, y especialmente de los servicios urbanísticos locales, sea el adecuado a los intereses generales en cumplimiento del mandato constitucional que subordina al interés general toda la riqueza del país (artículo 128-1); de modo que se eviten exclusiones y el abuso de una posición dominante en el mercado, o expectativas que distorsionen el mercado, creando situaciones tanto del soporte físico sobre el que se ha de establecer el servicio, como es el suelo y la red que por el circule, como del servicio mismo.

\section{Configuración de un modelo de autorización o licencia reglamentada}

El problema más importante que plantea el régimen de autorización de servicios con reglamentación es el de garantizar en la prestación aquellos principios que tradicionalmente han caracterizado al servicio publico a los 
que hay que añadir otros que el Derecho comunitario incorpora, como son las de disponibilidad y permanencia del servicio y la adaptabilidad del mismo a las cambiantes innovaciones tecnológicas: y, además, aquellos otros que el Derecho de la Unión Europea exige en el régimen de libre concurrencia como el de objetividad, no discriminación y transparencia.

Para conseguir estos objetivos los medios de control que pueden ser utilizados son, en esquema, los siguientes:

\section{La utilización de la reglamentación}

Por vía reglamentaria se pueden conseguir los mismos objetivos que por vía contractual se podían alcanzar al establecer o fijar las obligaciones del concesionario con relación a la Administración y a los usuarios.

El Reglamento de Servicios de las Corporaciones Locales ya establecía un esquema de estas obligaciones del concesionario.

Lo peculiar de la nueva situación estriba en que la reglamentación e incluso los mandatos de la Administración que el particular autorizado debe cumplir se extienden a aspectos tan esenciales en el Derecho comunitario como el de transparencia en el mercado o la eliminación de medidas que puedan determinar su control por alguno de los operadores, tal como ocurre en la concesión. A ello se incorporan las actuaciones administrativas encaminadas a conseguir la adaptación del servicio a la cambiante tecnología, como obligación especifica de la empresa autorizada.

\section{La creación de Organismos o Comisiones ad hoc, para controlar el funcionamiento del servicio de interés público}

Es preciso una organización específica para conseguir que el funcionamiento del servicio se adapte a los principios enunciados en las normas reguladoras del Servicio y con los mandatos de la Administración y, además, respete la transparencia del mercado.

Estos órganos de control externo pueden estar compuestos por representantes de la Administración e incluso de los usuarios del servicio.

Así, en España, en materia de telecomunicaciones, existe una Comisión del Mercado de las Telecomunicaciones que controla que las actividades autorizadas respeten las normas de competencia, y las relaciones entre las empresas en la medida que afecten a intereses generales. 


\section{Control de las condiciones de instalación y acceso a las redes publicas}

Igualmente es necesario que la Administración local regule y controle las condiciones de interconexión y acceso a la redes publicas, cuando éstas permitan su utilización por varios operadores del mercado. Las vías públicas integradas en el dominio publico han adquirido mayor importancia como elementos que facilitan la distribución de servicios. Las denominadas «galerías de servicios», establecidas generalmente en grandes municipios en las que confluyen redes e instalaciones de todo tipo, han de ser utilizadas como un medio para conseguir la posible participación en el mercado de distintos operadores económicos y no como un instrumento para determinar situaciones de exclusividad en la prestación. La Administración Local ha de controlar además la posibilidades de interconexión y el acceso a estas redes cuando estas sean públicas, circulando por ellas los elementos propios del servicio (cableado), cuya conservación corresponde a la empresa autorizada.

\section{Implantación por, vía reglamentaria, de un «servicio universal» al que tienen derecho todos los ciudadanos}

La Administración local además ha de velar porque el servicio público local se preste en condiciones de igualdad a todos los ciudadanos, y con un carácter de permanencia y disponibilidad. Los titulares de servicio disponibles al publico y los titulares de redes publicas, para cuya prestación, instalación y explotación se requiera licencia individual, han de sujetarse al régimen de obligaciones de servicio público, cuyo cumplimiento por la empresa ha de ser controlado por el organismo creado al efecto.

Las obligaciones de servicio público comprenden, de una parte, el denominado «servicio universal» $\mathrm{y}$, de otra, los servicios que obligatoriamente exija la Administración al operador económico. Cuando estas obligaciones supongan cargas para el prestador que excedan de las que normalmente asuma cualquier empresario ha de ser compensado económicamente el operador que las soporte.

Por servicio universal se entiende el conjunto de servicios con una calidad determinada, accesibles a todos los usuarios, con independencia de su localización geográfica, a un precio asequible. Servicio accesible y precio asequible han de ser fijados por la Administración, en función de la evolución tecnológica, de la demanda de servicios en el mercado o por consideraciones de política social o territorial. 
El servicio universal ha de ser financiado con criterios de no discriminación, proporcionalidad y transparencia entre todos los operadores del servicio ${ }^{14}$.

Si un operador determinado se encontrase en desventaja competitiva, derivada de la obligación de la prestación del servicio universal, puede ser compensado por el resto de los operadores de las pérdidas ocasionadas por la prestación del servicio universal.

Si los servicios son de naturaleza urbanística los costes de las obras se integran en los denominados «costes de urbanización», compensables conforme a esta legislación y exigibles mediante cuotas a los beneficiarios de la urbanización, promovida por el urbanizador.

Si no se tratase de servicios urbanísticos cabe admitir la compensación a través de fondos especialmente destinados a este efecto.

\section{Posibilidad de establecer obligaciones específicas}

Además de las obligaciones generales que supone el servicio universal, es posible establecer obligaciones específicas, cuya financiación debe ser compensada económicamente, salvo que la reglamentación del servicio las contemple específicamente como una obligación de la persona o Entidad autorizada.

\section{Delimitación de un espacio (sector, área o unidad de urbanización) que compense los desequilibrios financieros entre operadores}

El equilibrio financiero entre operadores no se mantiene por la Administración sino por el resto de operadores en el mercado en un área o sector de compensación determinado, o en una «Unidad de Urbanización»si nos encontramos ante servicios urbanísticos. El equilibrio financiero sólo puede ser operativo como tal principio para compensar obligaciones de servicio de interés general, pero no opera como instrumento equilibrador de posibles pérdidas durante un determinado periodo, dado que las licencias tienen un carácter indefinido. Existe la obligación de compensar a la empresa autorizada por el resto de los operadores, si las obligaciones de

\footnotetext{
${ }^{14}$ Como ejemplo puede ser examinada la Ley General de Telecomunicaciones sobre las características de este servicio.
} 
servicio suponen un sacrificio especial para el operador. Esta compensación puede ser realizada por Fondos especialmente constituidos o por los sistemas urbanísticos de actuación.

Si no existiese un Fondo de equiparación entre operadores y se exigiese al prestador del servicio una prestación particular que no esté obligado a realizar según las condiciones generales del servicio universal, es razonable que deba ser compensado por la Administración.

\section{Utilización indistinta de la vía unilateral o contractual para conseguir los objetivos marcados por la Administración}

El régimen general sería el de licencia o autorización, pero nada excluye que por vía contractual se pacten obligaciones específicas no incluidas en el régimen de «servicio universal» y que incluso determinados efectos de la licencia se regulen de forma negociada.

\section{Establecimiento o extensión de un sistema tributario de tasas por las licencias otorgadas}

Las autorizaciones y licencias permiten a la Entidad Local la obtención de importantes ingresos por vía de tasas, cuyo rendimiento puede quedar afectado especialmente a fines de interés social o a la prestación de actividades sociales o asistenciales no asumidas por la iniciativa privada. Así, podrían ser constitutivas de fondos especiales para la urbanización de terrenos o para la ejecución de obras sociales.

9. Las licencias que tengan un carácter limitado por suponer la utilización especial o privativa del dominio publico deben otorgarse previa licitación, conforme al principio de transparencia en la actuación administrativa.

Esta precisión que ya estaba contemplada en el antiguo Reglamento de Bienes de las Corporaciones Locales de 27 de mayo de 1955 (artículo 62), se recoge también en el vigente Reglamento de Bienes de las Entidades Locales aprobado por Real Decreto 1372/1986 de 13 de junio, para las licencias por usos comunes especiales. Norma ésta de aplicación en el caso de los servicios económicos cuando la utilización de bienes de uso público fuese solo la base necesaria para la prestación de un servicio público municipal o provincial. 


\section{CONCLUSIÓN}

Este modelo no deja de presentar indudables dificultades prácticas, aunque también ventajas para la iniciativa particular e interés general.

En primer lugar, pasar de un régimen concesional a un régimen de autorizaciones comporta la transformación de títulos ya existentes, sin crear desigualdades entre los antiguos y los nuevos operadores en el mercado. Además, es necesario que exista un control efectivo e intenso de la Administración en las actividades autorizadas.

Lo que no parece admisible es que la Administración Local otorgue la gestión de los servicios económicos particulares, con escaso o nulo control administrativo, servicios económicos de tan indudable impacto social, como son el abastecimiento y distribución de aguas, el tratamiento de aguas residuales, y otros esenciales de naturaleza económica, suponen unos elevados rendimientos económicos.

La Administración Local encuentra su justificación en la prestación de servicios básicos al ciudadano, muchos de ellos de carácter económico. Esto no quiere decir que sea la propia Administración quien los preste pero sí, al menos, quien los controle adecuadamente. No resulta conforme a Derecho, salvo en los casos de monopolios naturales, una situación de monopolio en la prestación de servicios cuando es posible la competencia entre los mismos. La concesión debe dejar paso a formas de autorización más o menos reglamentadas en las que los intereses generales sean salvados mediante obligaciones universales o generales de servicio público, establecidas por vía reglamentaria, o mediante particulares condiciones en el título habilitante e incluso por vía contractual.

Las actividades privadas de interés público no solo pueden estar sometidas a una fuerte reglamentación, sino que además a través del condicionado de la autorización pueden ser controladas mediante cláusulas o elementos accidentales con los que se puede llegar a los mismos resultados prácticos que se obtienen a través de la concesión ${ }^{15}$.

En el régimen de las autorizaciones administrativas la gestión económica se basa en las decisiones de los agentes económicos en el marco de un mercado organizado por la Administración para garantizar que el servicio se

\footnotetext{
15 J.A. Manzanedo, J. Hernando y E. Gómez Reino, Curso de Derecho Administrativo Económico, I.E.A.L. 1970, p. 703. Son las denominadas autorizaciones operativas que suponen el interesamiento permanente de la Administración en la actividad.
} 
preste en las mejores condiciones posibles. No se considera necesario que la Administración se reserve para sí el ejercicio de ninguna de las actividades que integran el suministro del servicio. Se abandona así la noción de servicio publico, tradicional en nuestro ordenamiento, sustituyéndola por garantías de servicio que la Administración cuida de controlar en sus aspectos de suministro regular y continuo, calidad del servicio y producción al menor coste posible constituye. Un ejemplo en este sistema la regulación del sector eléctrico por Ley de 27 de noviembre de 1997. (BOE de 28 de noviembre de 1997). Es más, la Administración, a veces, garantiza incluso a los ciudadanos que su prestación no supere unos determinados precios máximos, que revisa periódicamente en razón al incremento de las costes de producción y distribución (así ocurre en materia de gases licuados del petróleo). Esta revisión, empero, no se justifica por el mantenimiento del «equilibrio financiero» propio de la concesión, sino que puede obedecer a otras motivaciones de índole social o económica, manteniéndose la libertad de mercado con precio máximo controlado, hasta ese límite. En el régimen de control mediante autorización, la Administración se limita su actividad a regular por vía reglamentaria las condiciones en que se ha de prestar el servicio y las prestaciones que son exigibles a la entidad autorizada, en beneficio de la colectividad, controlando incluso los contratos de prestación. Así ocurre en materia de seguridad privada, regulada por la Ley de 30 de julio de 1992 y su Reglamento, aprobado por Real Decreto de 9 de diciembre de 1994 y más recientemente en materia de Telecomunicaciones.

Las Entidades Locales gozan de la potestad reglamentaria y por esta vía pueden controlar el funcionamiento de los servicios de su competencia, sin necesidad de acudir a la vía de la concesión, que supone la obtención de algún privilegio económico por la vía de la exclusividad. Los precedentes de la Administración estatal pueden servir de pauta en esta labor.

El incremento de modos y técnicas de control no debe suponer una despublificación de la regulación de la actividad económica. Son principios clásicos en la creación y funcionamiento de los servicios públicos el de continuidad; el de igualdad, que prohíbe la discriminación de los usuarios; el de adaptación a las necesidades del momento, que justifica en determinados casos la inexistencia de derechos adquiridos para el mantenimiento de la reglamentación establecida; el de mutabilidad de los contratos administrativos con garantías para el contratista; el de objetividad, y consiguiente neutralidad que deben observar cada una de las personas que colaboran en un servicio público.

Pues bien, estos principios merecen ser mantenidos e incluso pueden ser incorporados a las técnicas administrativas de control, superando 
barreras dogmáticas. Sería inadecuado sostener que los principios clásicos del servicio público deben ceder ante el impacto de otras técnicas administrativas que se centran en la vía del control de la iniciativa privada pero que no menoscaban los citados principios.

Estos principios pueden ser incorporados a la actividad de control de la iniciativa privada, principalmente a través de la reglamentación. 